\title{
Strongyloides westeri and Parascaris equorum: Observations in field studies in Thoroughbred foals on some farms in Central Kentucky, USA
}

\author{
E. T. LYONS*, S. C. TOLLIVER
}

\author{
Department of Veterinary Science, University of Kentucky, Gluck Equine Research Center, Lexington, \\ KY 40546-0099, *E-mail: elyons1@uky.edu
}

\begin{abstract}
Summary
Observations were made on the intestinal threadworm (Strongyloides westeri) and ascarid (Parascaris equorum) in field studies in 373 Thoroughbred foals on nine farms in Central Kentucky (USA) in 2013. Qualitative examination was made of feces of the foals for presence of $S$. westeri and $P$. equorum eggs. The main purpose of the prevalence study was to obtain current data on $S$. westeri in Thoroughbred foals. This was done to compare these findings with earlier studies in this geographical area where the prevalence of this parasite has been very low the last several decades. All the foals except on one farm had been treated one or more times with a parasiticide before the study. Prevalence of $S$. westeri in foals was 0 to $3 \%$ on two farms, 6 to $9 \%$ on three farms, and 20 to $51 \%$ on four farms. The prevalence of $P$. equorum in foals was 0 to $14 \%$ on three farms, 27 to $38 \%$ on three farms, and 46 to $51 \%$ on three farms. Effect of drugs given before the current study, on the prevalence of the two parasitic nematode species, is discussed. Also, three field tests were done by the present authors to evaluate activity of three individual or combination of drugs against ascarids. Evaluation was somewhat limited because, on two of the farms, a relatively small number of foals was passing ascarid eggs before treatment. However, oxibendazole and oxibendazole/piperazine combination were much more efficacious than fenbendazole.
\end{abstract}

Keywords: field studies; Strongyloides westeri; Parascaris equorum; prevalence; parasiticides; Thoroughbred foals; Kentucky; 2013

\section{Introduction}

Two nematode species (Strongyloides westeri and Parascaris equorum), found world-wide in equids, were studied by the present authors in Thoroughbred foals relative to prevalence and drug efficacy. Special interest on preva- lence of $S$. westeri was to determine if the very low occurrence of infected foals the last several decades still persisted. (Lyons et al., 2006). Strongyloides westeri, located as an adult in the small intestine, is the first nematode to mature in foals. The prepatent period is about two weeks. Research on the life cycle of $S$. westeri has shown that milk transmission of parasitic third stage larvae, the probable main source of infection in foals, can be prolonged up to over 40 days post partum (Lyons et al., 1973). This parasite has been incriminated as a cause of diarrhea in foals but this is debatable. Parascaris equorum can definitely be pathogenic in foals. It can produce ill health but also can kill foals by affecting the small intestine by impaction and rupture of the wall, resulting in peritonitis. Ascarids have a simple life cycle. Foals ingest, along with food, larvated eggs which can survive for long periods in the environment. Larvae hatch from the eggs in the foal gastrointestinal tract (GIT), then migrate and cause damage as they go through the liver and lungs, undergoing development there, after which they return to the GIT and mature in the small intestine in about $10-12$ weeks (Drudge \& Lyons, 1989.)

Outcome of the present research was to provide comparison of the current prevalence of especially strongyloides but also ascarids with that of some of the last such studies here (Lyons \& Tolliver, 2004; Lyons et al., 1993, 2006). Another goal was to try and interpret the effect of parasiticides used prior to the study on the prevalence of these parasites. Also, there was special interest in evaluating activity of three individual or combination of compounds against ascarids in three field tests done by the present authors in the current study.

\section{Materials and methods}

Field studies were done for determination of prevalence of S. westeri and P. equorum in 373 Thoroughbred (TB) foals 


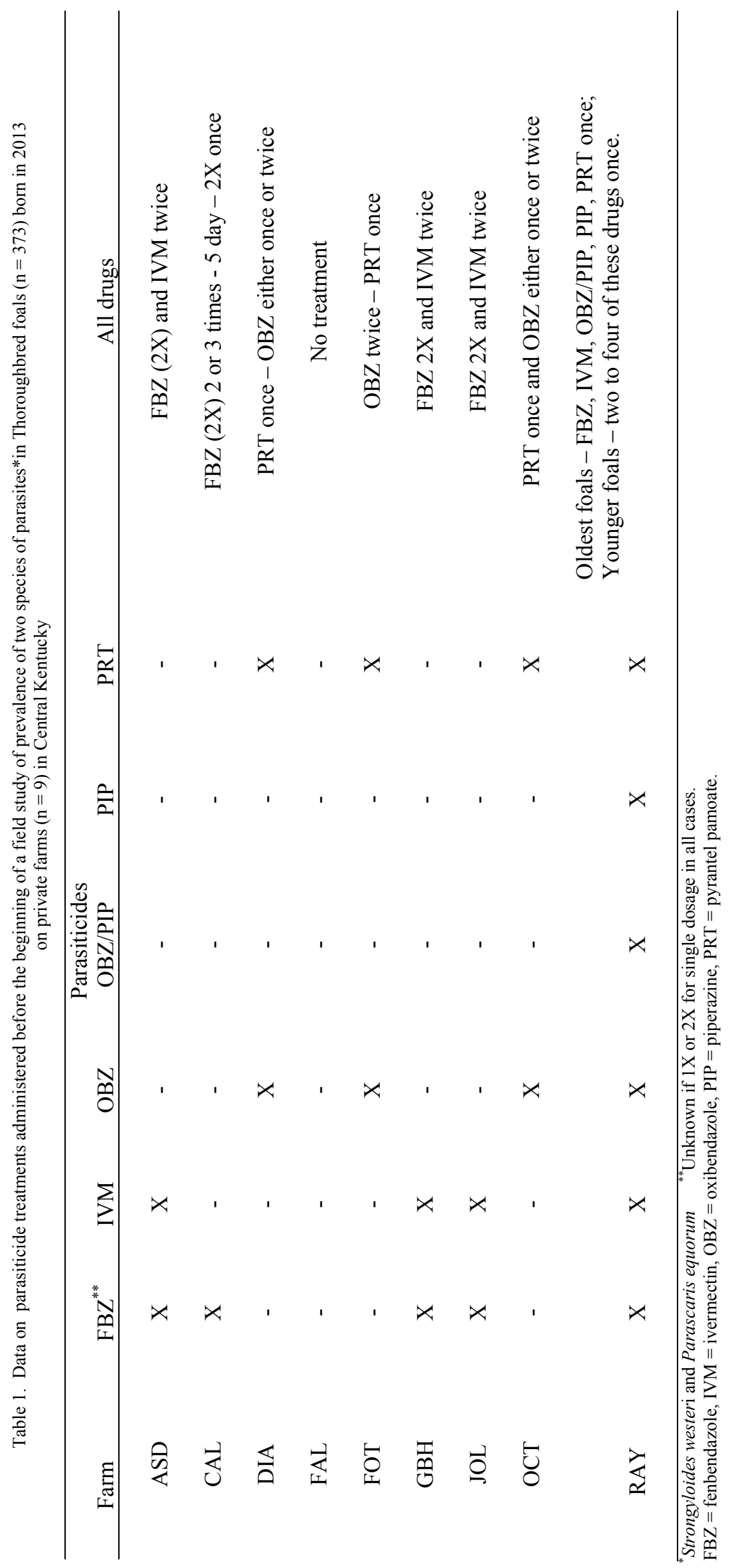




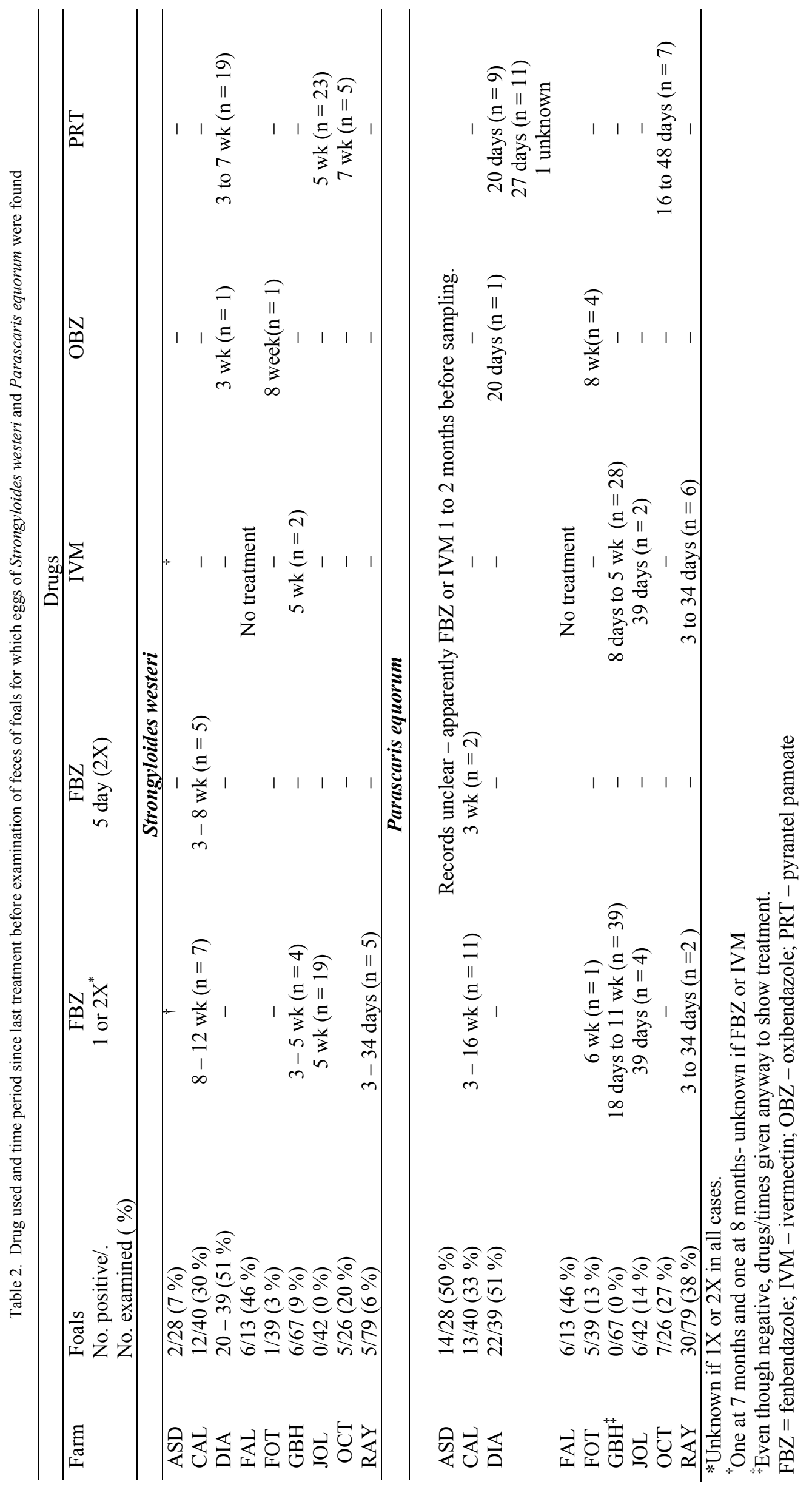


on nine farms in Central Kentucky between July 11 and October 7, 2013. Ages of the foals at the time of the study were not obtained. However, Thoroughbred foals are typically born between January and June with the peak in early Spring months. Since the foals in the study were sampled between July and October, probably they averaged about six months old. Fecal samples were collected from the stall floor or rectally for each foal. Qualitative examination of the feces for parasite eggs was done according to published methodology (Lyons et al., 1988). Personnel on each farm, or a veterinarian, provided and administered the parasiticides to each foal. Treatment was before a parasitologic examination of feces was made. This means that no pretreatment fecal samples were examined before beginning of this part of the prevalence study. Paste formulations of fenbendazole (FBZ), ivermectin (IVM), oxibendazole (OBZ), and pyrantel pamoate (PRT) were given intraorally. Besides the prevalence study, the present authors did three field tests, one each on farms ASD, DIA, and RAY, to obtain data on activity on ascarids comparing efficacy of FBZ (2X), OBZ, and OBZ/piperazine combination. Fecal samples were examined for parasite eggs on the day of treatment (just before administration of a drug) and 13 - 15 days later. FBZ and OBZ were commercial paste formulations given intraorally. A $34 \%$ liquid piperazine adipate preparation at $56 \mathrm{mg}$ base $/ \mathrm{kg}$, used off label, was administered intraorally via stomach tube by the attending veterinarian on Farm RAY. Further details on parasiticides used are listed (Tables $1-3$ ).

\section{Results and discussion}

Prevalence of $S$. westeri in foals was 0 to $3 \%$ on two farms, 6 to $9 \%$ on three farms, and 20 to $51 \%$ on four farms (Table 2); average prevalence was $15 \%$. Even though only a qualitative method was used and, therefore, $S$. westeri eggs were not counted as per gram of feces (EPGs), very few eggs were found for each positive foal. Comparing average prevalences to two previous studies here, the lowest value for the two farms were similar to 2003 and 2004 data (Lyons \& Tolliver, 2004; Lyons et al., 2006) and the next highest on the three farms were like that found in 1992 (Lyons et al., 1993). While the prevalences for the other four farms was much higher than the aforementioned five farms, it was much lower than the over $90 \%$ recorded here before the marketing of efficacious drugs to control these parasites (Todd et al., 1949). Probably, the prevalence on five of the farms was low because the foals were treated with OBZ or IVM before the current study. Treatment of these foals was with IVM twice on three of the farms (ASD, GBH, and JOL), with OBZ twice on one of the farms (FOT), and with OBZ and IVM once on one farm (RAY). Excellent activity against $S$. westeri by these two compounds would not be unexpected because currently OBZ at the dose rate of $15 \mathrm{mg} / \mathrm{kg}$ (Drudge et al., 1983) and IVM at the therapeutic dose rate of $200 \mu \mathrm{g} / \mathrm{kg}$ are the only two compounds labeled for control of these nematodes in the USA (Drudge \& Lyons, 1989; Ludwig et al., 1983; Ryan \& Best, 1985).

Remarks about the farms with the higher prevalences of $S$. westeri follow. For foals on Farm OCT with $20 \%$ of them infected at the time of the study, OBZ was given to nine of them 15 days earlier and the other 70 at two to five months earlier. The only positives had been treated with PRT at about seven weeks earlier. The much higher prevalence in PRT-treated foals was not unanticipated because of its known inactivity against $S$. westeri (Drudge et al., 1981a). Farm CAL foals were only treated with FBZ and 30\% were infected. This was not surprising because FBZ is ineffective on $S$. westeri at therapeutic dose rates, but a single treatment at $50 \mathrm{mg} / \mathrm{kg}$ dose rate is highly effective (Drudge et al., 1981b).

On Farm DIA with infection rate of $51 \%$, OBZ was administered to 10 foals at 21 to 60 days earlier (only one infected). The remainder of foals were treated at the same time with PRT and 19 were infected which was not unexpected (Drudge et al., 1981a). Farm FAL treated none of their foals before our study and $46 \%$ were positive. It is noteworthy that none of the foals on these four farms had been treated with IVM. This probably was because ascarids are now resistant to IVM (Hearn \& Peregrine, 2003), so it is used less at this time in foals. Conclusion from the S. westeri study is that both OBZ and IVM still seem to be effective when used often enough. The increase of prevalence on some of the farms was probably because of lessened use of these drugs in foals. This is reflected by much lower prevalence on some of the farms when these compounds were used and used often.

The prevalence of $P$. equorum in foals was 0 to $14 \%$ on three farms, 27 to $38 \%$ on three farms, and 46 to $51 \%$ on three farms (Tables 2). Average prevalence was $28 \%$ which was similar to results found in 2003 here (Lyons \& Tolliver, 2004). The two farms with $13 \%$ or $14 \%$ prevalence may be related to FBZ and IVM having greater activity than on some other farms. The negative finding on farm GBH was like that found on two big farms with large numbers of foals here in 2003 (Lyons \& Tolliver, 2004); no obvious explanation was detected for this situation in either study. Activity of $27 \%-38 \%$ in foals on three farms probably was because of "reduced activity" of FBZ, IVM, and PRT. The three farms with foals with the highest prevalence can be attributed to no deworming on one farm (FAL) and likely to poor activity by FBZ, IVM, and PRT on the other two farms. When initially marketed, FBZ (2X), IVM, and PRT were highly effective on ascarids. FBZ was less active in this study than found in 2007 here (Lyons et al., 2008). PRT and IVM are essentially inactive on these parasites now (Hearn \& Peregrine, 2003; Lyons et al., 2008).

Three field tests by the present authors, evaluating efficacy of two individual compounds (FBZ and OBZ) and a combination of OBZ and PIP against compounds against ascarids, are summarized (Table 3). Evaluation was by determining the number of foals passing parasite eggs before and after treatment. Even though relatively small numbers of foals were positive for ascarid eggs before treatment in 
Table 3. Field tests by the present authors in foals on two farms (ASD and DIA) comparing activity of fenbendazole (FBZ) and oxibendazole(OBZ) and on one farm (RAY) evaluating activity of a combination of OBZ and piperazine(PIP) on two nematode species with main interest on ascarids

\section{Farm ASD}

Fenbendazole $(\mathrm{n}=14$ foals $) \quad$ Oxibendazole $(\mathrm{n}=14$ foals $)$

\begin{tabular}{lcccc}
\hline No. of foals positive & Ascarid & Strongyloides & Ascarid & Strongyloides \\
\hline Pretreatment $(10 / 2 / 13)$ & $6(43 \%)$ & $1(7 \%)$ & $8(57 \%)$ & $0(0 \%)$ \\
Posttreatment $(10 / 17 / 13)$ & $2(14 \%)$ & $2(14 \%)$ & $0(0 \%)$ & $0(0 \%)$ \\
\hline
\end{tabular}

Farm DIA

Fenbendazole $(\mathrm{n}=15$ foals $) \quad$ Oxibendazole $(\mathrm{n}=15$ foals $)$

\begin{tabular}{lcccc}
\hline No. of foals positive & Ascarid & Strongyloides & Ascarid & Strongyloides \\
\hline Pretreatment $(10 / 2 / 13)$ & $6(40 \%)$ & $1(7 \%)$ & $5(33 \%)$ & $3(20 \%)$ \\
Posttreatment $(10 / 17 / 13)$ & $4(27 \%)$ & $3(20 \%)$ & $0(0 \%)$ & $0(0 \%)$ \\
\hline
\end{tabular}

Farm RAY

Combination of oxibendazole and piperazine ( $n=79$ foals)

\begin{tabular}{lcc}
\hline No. of foals positive & Ascarid & Strongyloides \\
\hline Pretreatment $(9 / 26 / 13)$ & $29(37 \%)$ & $3(4 \%)$ \\
Postreatment $(10 / 9 / 13)$ & $0(0 \%)$ & $0(0 \%)$ \\
\hline
\end{tabular}

the two field tests comparing activity of FBZ and OBZ, the results were similar (Table 3 ). OBZ was $100 \%$ efficacious but FBZ much less so. The combination of OBZ and PIP was highly effective against ascarids. As mentioned in the prevalence study, FBZ was less active than found a few years ago. The excellent activity of OBZ has not seemed to decrease since this drug first became commercially available. PIP historically has been highly efficacious against ascarids but its routine use has been discontinued for many years (Drudge \& Lyons, 1989). In the present evaluation, it was not possible to judge the activity of PIP alone on ascarids because it was combined with the still highly efficacious ascaridicide OBZ. The number of foals shedding $S$. westeri eggs before treatment was very low but efficacy seemed typical of inactivity of FBZ but high activity of OBZ.

Even though, in the main prevalence study, no pretreatment fecal samples were examined for parasite eggs from foals, data are presented as informational findings on the day of the study. Prevalences, especially when positives are found after treatment, can provide a measure of the current status of drug efficacy. However, at the time of the study, in many cases there were long periods since drugs were used, so this must be considered in evaluation of drug activity.

Some limitations for the prevalence evaluation are that small numbers of foals were involved on some farms, no pretreatment fecal samples were examined, and sometimes there were long periods of sampling after drug treatment. However, the field studies provided some insight into the present activity of the commercially available parasiticides
(FBZ, IVM, OBZ, and PRT), particularly on S. westeri and ascarids in equids in this geographical area. Noteworthy is that prevalence of $S$. westeri has increased on some farms where IVM or OBZ are not used or used infrequently in foals. For ascarids, PRT and IVM continue to have low activity; FBZ activity seems to have diminished, but OBZ is still highly active. These data are applicable to other regions of the world.

\section{Acknowledgements}

This investigation (Paper No. 13-14-137) was made in connection with a project of the University of Kentucky Agricultural Experiment Station and is published with the approval of the director. Research in the animals used in the study was approved by the University of Kentucky Institutional Animal Care and Use Committee (IACUC) under Protocol 2008-0257.

\section{References}

DRUDGE, J. H., LYONS, E. T. (1989): Internal parasites of equids with emphasis on treatment and control. HoechstRoussel (Monograph); revision of 1986 issue. 26 pp.

Drudge, J. H., Lyons, E. T., Tolliver, S. C. (1981a): Parasite control in horses: a summary of contemporary drugs. Vet. Med. / Sm. An. Clin., 76: 1479 - 1489

Drudge, J. H., Lyons, E. T., Tolliver, S. C., Kubis, J. E. (1981b): Clinical trials with fenbendazole and oxibendazole for Strongyloides westeri infection in foals. Am. J. Vet. Res., 42: $526-527$ 
Drudge, J. H., Lyons, E. T., Tolliver, S. C., Kubis, J. E. (1983): Clinical trials of benzimidazoles for Strongyloides westeri infection in foals. Mod. Vet.Pract., 6: $414-417$

Hearn, P. P., Peregrine, A. S. (2003): Identification of foals infected with Parascaris equorum apparently resistant to ivermectin. J. Am. Vet Med. Assoc., 223: $482-$ 485. DOI: $10.2460 /$ javma.2003.223.482

Ludwig, K. G., Craig, T. M., Bowen, J. M., Ansari, M. M., LEY, W. B. (1983): Efficacy of ivermectin in controlling Strongyloides westeri infection in foals. Am. J. Vet. Res., 44: $314-316$

Lyons, E. T., Drudge, J. H., Tolliver, S. C. (1973): On the life cycle of Strongyloides westeri in the equine. J. $\mathrm{Pa}$ rasitol., 59: 780 - 787. DOI: 10.1007/s00436-003-1068-2

Lyons, E. T., Drudge, J. H., Tolliver, S. C. (1988): Natural infection with Eimeria leuckarti: prevalence of oocysts in feces of horse foals on several farms in Kentucky during 1986. Am. J. Vet. Res., 49: $96-98$

LyOnS E. T., Tolliver, S. C. (2004): Prevalence of parasite eggs (Strongyloides westeri, Parascaris equorum, and strongyles) and oocysts (Eimeria leuckarti) in the feces of Thoroughbred foals. Parasitol. Res., 92: $400-$ 404. DOI: $10.1007 / \mathrm{s} 00436-003-1068-2$
Lyons, E. T., Tolliver, S. C., Collins, S. S. (2006): Field studies on endoparasites of Thoroughbred foals on seven farms in central Kentucky in 2004. Parasitol. Res., 98: 496 - 500 DOI: 10.1007/s00436-005-0091-x

Lyons, E. T., Tolliver, S. C., Drudge, J. H., GranSTROM, D. E., Collins, S. S. (1993): Natural infections of Strongyloides westeri: prevalence in horse foals on several farms in central Kentucky in 1992. Vet. Parasitol., 50: 101 - 107. DOI: 10.1016/0304-4017(93)90010-K

Lyons, E. T., Tolliver, S. C., IOnitA, M., Collins, S. S. (2008):Evaluation of parasiticidal activity of fenbendazole, ivermectin, oxibendazole, and pyrantel pamoate in horse foals with emphasis on ascarids (Parascaris equorum) in field studies on five farms in Central Kentucky in 2007. Parasitol. Res., 103: 287 - 291. DOI: 10.1007/s00436008-0966-8

RYAN, W. G., BEST, P. J. (1985): Efficacy of ivermectin paste against Strongyloides westeri in foals. Vet. Rec., 117: 169 - 170. DOI: $10.1136 /$ vr.117.8.169

Todd, A. C., Kelley, G. W., Wyant, Z. N., Hansen, M. F., Hull, F. E. (1949): Worm parasites in Thoroughbred sucklings and weanlings. A survey of incidence, development and control. Kentucky Agriculture Experiment Station Bulletin, 541, 24 pp. 